\title{
Safety and Feasibility of Transcatheter Interruption of Ruptured Sinus of Valsalva Aneurysm Using the Cocoon Duct Occluder: Immediate Results and Mid-Term Follow-Up
}

\author{
Santosh Kumar Sinha ${ }^{\mathrm{a}, \mathrm{d}}$, Narendra Nath Khanna ${ }^{\mathrm{b}}$, Mahmadula Razi ${ }^{\mathrm{a}}$, Vinay Krishna ${ }^{\mathrm{a}}$, \\ Mukesh Jitendra Jha ${ }^{a}$, Vikas Mishra ${ }^{a}$, Puneet Aggarwala, Amit Goel ${ }^{\mathrm{a}}$, \\ Karandeep Singh ${ }^{\mathrm{a}}$, Ramesh Thakur ${ }^{\mathrm{a}}$, Lawrence Rajan ${ }^{\mathrm{c}}$, Chandra Mohan Varma ${ }^{\mathrm{a}}$
}

\begin{abstract}
Background: Limited data are available regarding safety and feasibility of transcatheter interruption of ruptured sinus of Valsalva aneurysm (RSOVA) using the Cocoon duct occluder (CDO) with immediate and mid-term follow-up result.

Methods: Transcatheter closure (TCC) was successfully done among eight patients, whereas five cases, not amenable to TCC, were referred for surgical correction among 13 consecutive patients of RSOVA at LPS Institute of Cardiology, Kanpur between January 2010 and March 2015.

Results: Their mean age was $26.1 \pm 6.9$ years. Sites of rupture were from right coronary sinus (RCS) to right atrium (RA) in one (12.5\%), right ventricle in one $(12.5 \%)$, and non-coronary sinus to RA in six patients $(75 \%)$. The defects $(9-17 \mathrm{~mm})$ were closed by CDO $(12 / 10$ - 20/18 mm) with 100\% procedural success. During follow-up (9 - 26 months), there was no residual shunt, progression of $A R$, infective endocarditis or device embolization.
\end{abstract}

Conclusion: TCC of RSOVA appears to be a safe and feasible alternative to surgical therapy, with high technical success and excellent mid-term follow-up.

Keywords: Sinus of Valsalva aneurysm; Amplatzer duct occluder; Cardiac device; Endocarditis; Cocoon duct occluder; Transcatheter closure

\section{Introduction}

Ruptured sinus of Valsalva aneurysm (RSOVA), though rare,

Manuscript submitted June 7, 2017, accepted June 19, 2017

a Department of Cardiology, LPS Institute of Cardiology, G.S.V.M. Medical College, Kanpur, Uttar Pradesh 208002, India

${ }^{\mathrm{b}}$ Apollo Indraprastha Hospital, New Delhi, India

${ }^{\mathrm{c} C o m m u n i t y ~ H e a l t h ~ C e n t r e, ~ G r e e n v i l l e, ~ K Y, ~ U S A ~}$

${ }^{\mathrm{d} C o r r e s p o n d i n g ~ A u t h o r: ~ S a n t o s h ~ K u m a r ~ S i n h a, ~ D e p a r t m e n t ~ o f ~ C a r d i o l-~}$ ogy, LPS Institute of Cardiology, G.S.V.M. Medical College, Kanpur, Uttar Pradesh 208002, India. Email: fionasan@rediffmail.com

doi: https://doi.org/10.14740/cr568w relatively more common in Asians, is a well-described clinical entity [1]. Aneurysms mostly arise from right coronary sinus (RCS) in 70\%, non-coronary sinus (NCS) in $29 \%$, and rarely from left coronary sinus in $1 \%$ [2]. It is usually congenital in origin with a tendency to rupture into the rightsided chambers of the heart, resulting in a left-to-right shunt with a profound hemodynamic effect with symptoms of palpitation, heart failure to sudden death in nearly $80 \%$ if left untreated [3]. Since the first report of device closure of RSOVA in 1994, it is increasingly being reported as either case reports or case series and is gradually replacing surgical correction with cardiopulmonary bypass, conventionally the mainstay of treatment [4-7]. Transcatheter closure (TCC) had been performed using Amplatzer duct occluder (ADO), ventricular septal defect (VSD) occluder, atrial septal defect (ASD) occluder, Gianturco coils and Rashkind umbrella [813]. Our study describes the experience of immediate and mid-term follow-up of TCC of RSOVA with Cocoon duct occluder (CDO; Vascular Innovations, Nonthaburi, Thailand).

\section{Materials and Methods}

\section{Patient characteristics}

This was a prospective, single-center study conducted in the Department of Cardiology, LPS Institute of Cardiology, G.S.V.M. Medical College, Kanpur, UP, India between January 2010 and March 2015. Thirteen consecutive patients of RSOVA were admitted during this period, of whom five were referred for surgical correction due to associated VSD in three, moderate aortic regurgitation (AR) in one, and rupture into left ventricle in one. Eight patients were chosen for TCC of RSOVA with CDO (Vascular Innovations, Nonthaburi, Thailand). All patients underwent comprehensive evaluation including chest X-ray, electrocardiogram, transrthoracic echocardiography (TTE) and intraprocedural transesophageal echocardiography (TEE) with colour Doppler interrogation by Vivid 7TM GE (Siemens, Germany) ultrasound system. RSOVA was diagnosed by aneurysmally dilated respective sinus of origin and continous flow with its communication into either right atrium (RA), right ventricular outflow tract (RVOT) or left ventricle 


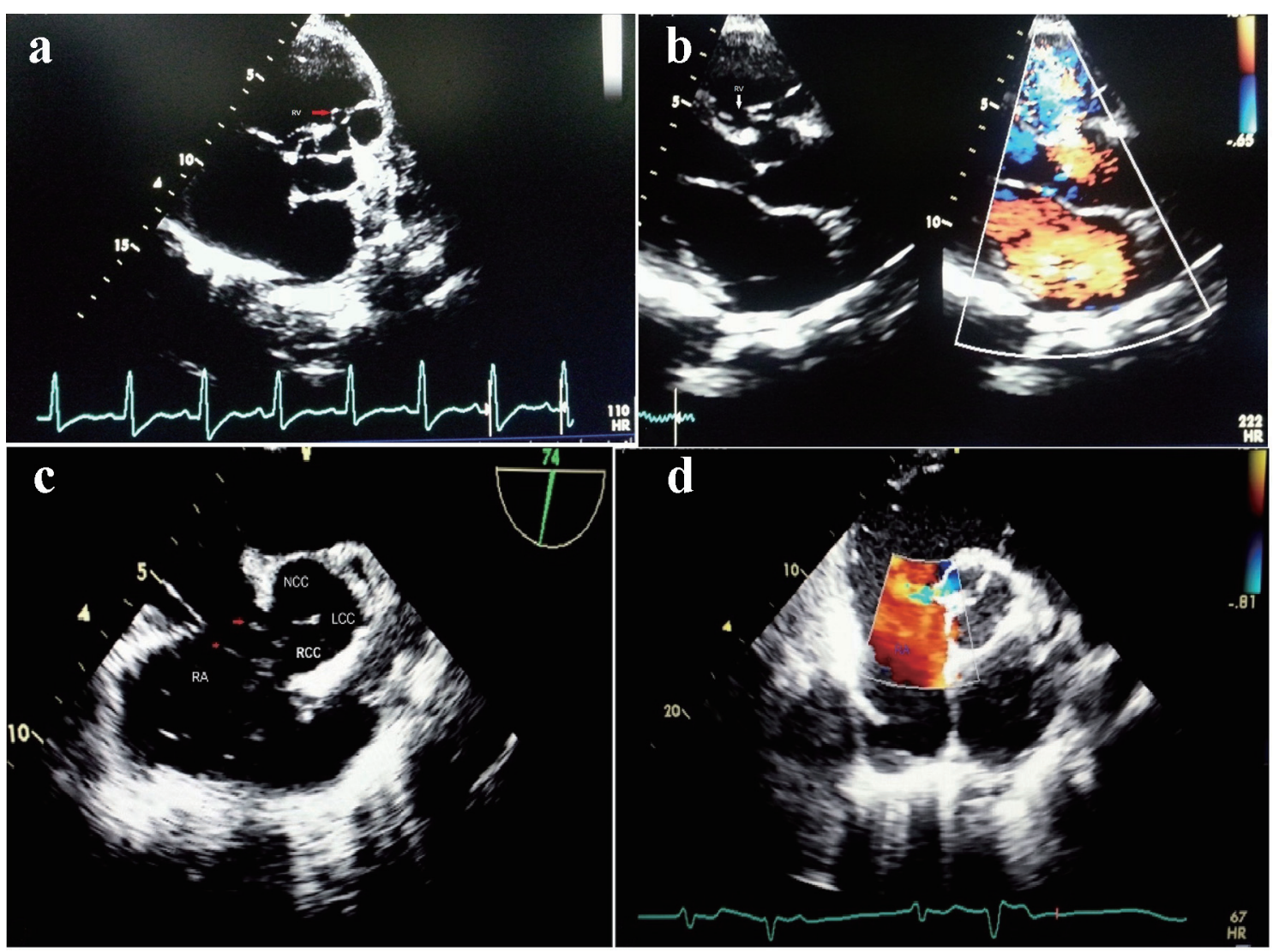

Figure 1. TTE view showing SOVA arising from right coronary cusp into right ventricle $(a, b)$; non-coronary cusp rupturing into right atrium on TEE view (c, d).

revealing a classical windsock deformity (Fig. 1a, b, c, d, Supplementary video 1, www.cardiologyres.org). The diameter of the RSOVA was measured at the aortic end as well as at the site of rupture. Informed consent was obtained from all.

\section{Procedure}

All procedures were performed under local anesthesia under TTE guidance. The femoral vein and artery were accessed by 8-F and 5-F sheath, respectively. Intravenous heparin (100 IU/ $\mathrm{kg}$ ) and teicoplanin $400 \mathrm{mg}$ were given. Aortic root angiography was performed by 5-F pigtail catheter. The left anterior oblique with cranial tilt projection was preferred for RSOVA draining into RA, right anterior oblique view for RSOVA rupturing into RVOT and few tailored view depending on the need (Fig. 2a, b). The RSOVA was measured at its aortic end by angiography using quantitative coronary angiography (QCA) and TEE. The larger of the two measurements was considered for device selection. The size of the CDO selected was such that its aortic segment was $2-4 \mathrm{~mm}$ larger than this diameter.

The defect was crossed from the aortic side using a 5-F Judkins right (JR) coronary catheter over a 0.035 " straight tip glide wire (Terumo Inc., Japan). With catheter across RSOV, exchange length wire $\left(330 \mathrm{~cm}, 0.035^{\prime}\right.$ Terumo wire) was passed into RA or RVOT and snared with $2 \mathrm{~cm}$ EN Snare
Endovascular Snare System (Merit Medial, USA) (Fig. 3a, b) bringing wire out of right femoral venous sheath, thereby establishing a stable arteriovenous wire loop (Fig. 3c). A 10to 12 -F long Cocoon delivery sheath (Vasc Innovation, Thailand) depending on the size of the device was introduced over the exchange length wire from the venous side into ascending aorta across the defect (Fig. 3d). CDO with its attached delivery cable was then inserted through the delivery sheath, and its aortic disk was deployed in the ascending aorta. The whole assembly was pulled back and positioned carefully till the aortic disk blocked the aortic end of the SOVA (Fig. 4) and it was ensured that aortic valve leaflets were free as seen on TEE. After confirming the precise placement, the rest of the CDO was deployed on the right side across the defect. During this maneuvre, a gentle traction was exerted on the delivery cable, but taking special care to ensure seating of the aortic disk on the aortic side without slippage into the aneurysm. After 10-min delay, aortic root angiogram was again performed to ensure proper device position and make certain that there was no significant AR, tricuspid regurgitation (TR), paradevice leak or any encroachment on right coronary artery if RSOVA was arising from right coronary cusp (RCC) which was also confirmed on TEE (Figs. 4 and 5a, b, c, d). The CDO was then released from the delivery cable by turning the cable counter clockwise using the pin vise (Fig. 6a, b, c, d). TTE was performed next day to look any residual flow across the 


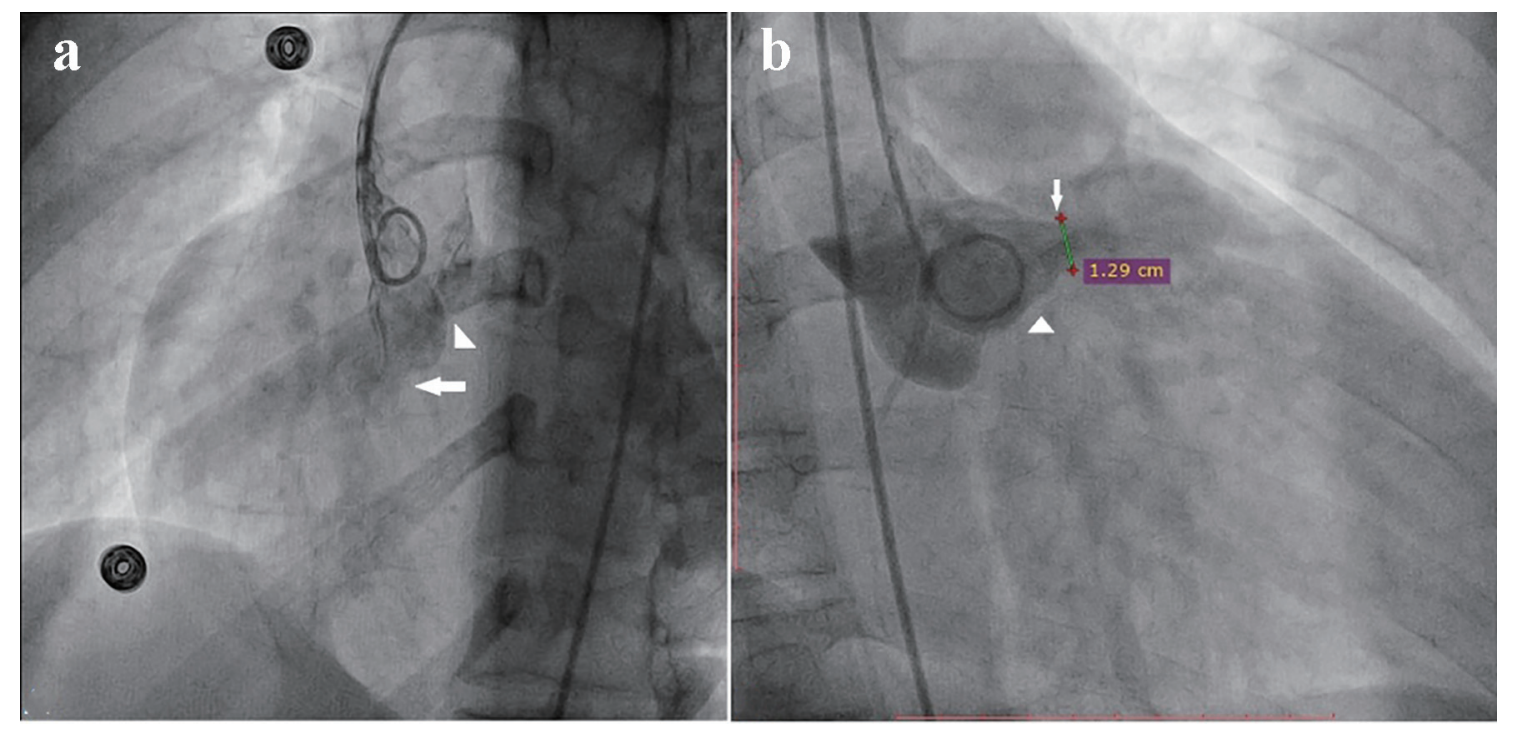

Figure 2. Antero-posterior view showing SOVA from NCC rupturing into RA (a). Right anterior oblique view showing SOVA from $\mathrm{RCC}$ rupturing into RV (b).

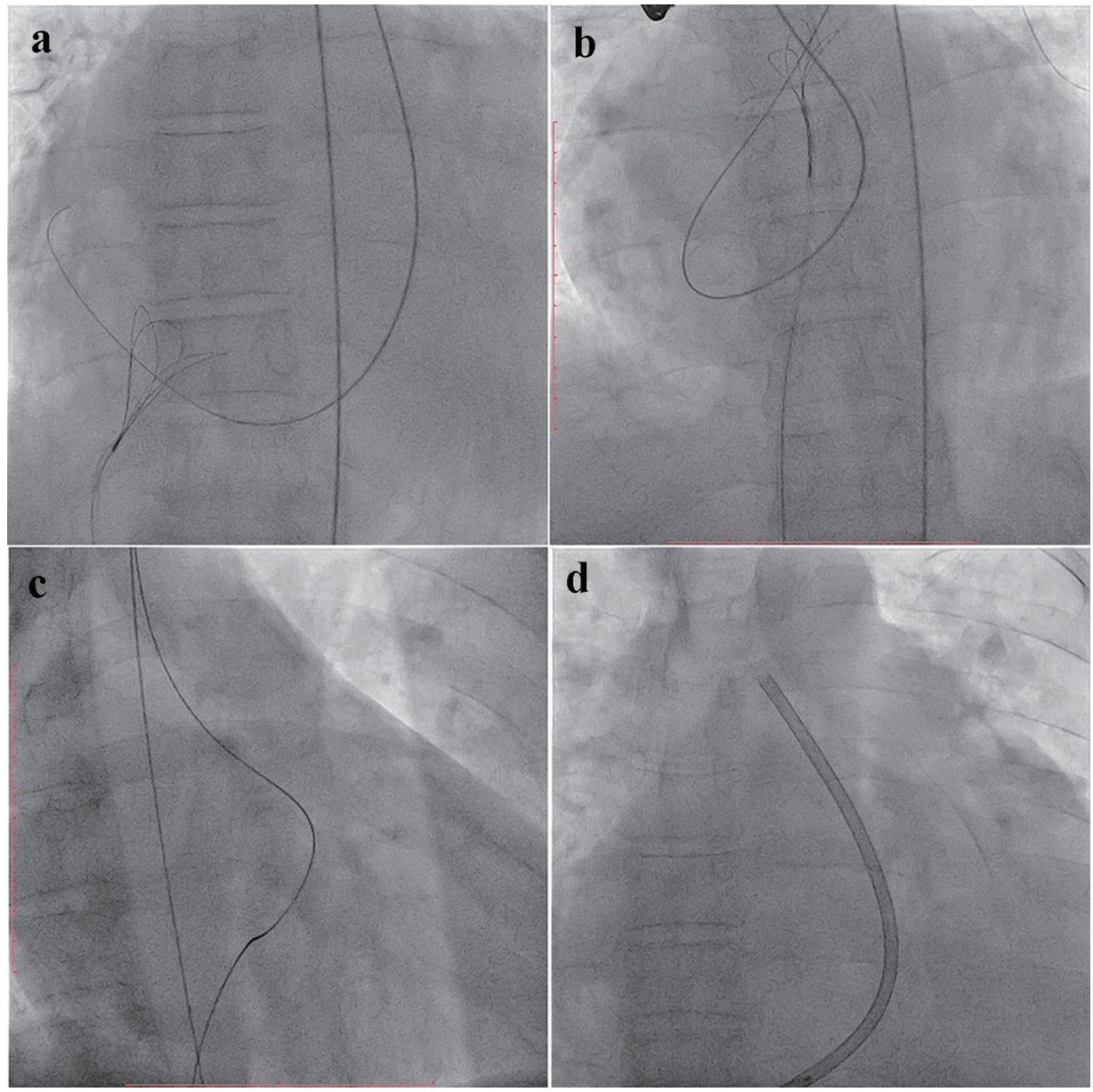

Figure 3. Fluoroscopic view showing wire being snared from right atrium (a), right ventricular outflow tract (b), arterio-venous loop (c), and delivery sheath seen into ascending aorta (d). 


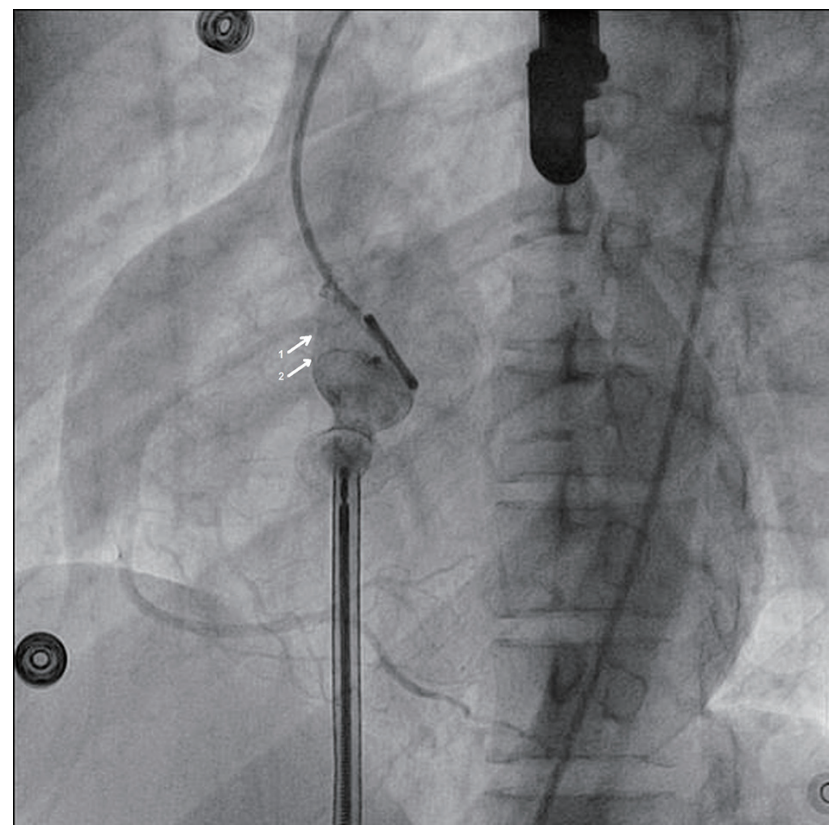

Figure 4. Aortic root angiogram showing right coronary artery arising above the defect (1); CDO attached to cable with aortic end in right coronary cusp (2). device. All patients were discharged in stable position on next day with advice of aspirin $75 \mathrm{mg}$ once daily for 6 months. They were studied clinically and by TTE at discharge, 1, 3, 6 months, and annually thereafter. Procedure-related AR was defined as the occurrence of any grade of new AR or worsening by more than one grade of pre-existing AR.

\section{Results}

The patient characteristics are summarized in Table 1. There were five males $(60.3 \%)$ and three females $(39.7 \%)$, with the male to female ratio of $2: 1$. The mean age in transcatheter group was $26.1 \pm 6.9$ years (median, 26.5 years). Patients were in either New York Heart Association (NYHA) class III or IV at presentation. The associated defects were bicuspid aortic valve in one patient, mild pre-existing AR in two patients, and healed infective endocarditis (IE) in one patient and right ventricular dysfunction with severe TR. All patients received adequate medical management before cardiac catheterization and device closure. Mean defect size was 13 mm (range: 9 - 17 $\mathrm{mm}$; mean $9 \pm 1.3 \mathrm{~mm}$ ) which was closed with TEE assistance by CDO (range: 12/10 - 20/18 mm; median: 13/11 mm). Six of the eight patients $(75 \%)$ had defects communicating between non-coronary cusp (NCC) and RA, one patient (12.5\%) had

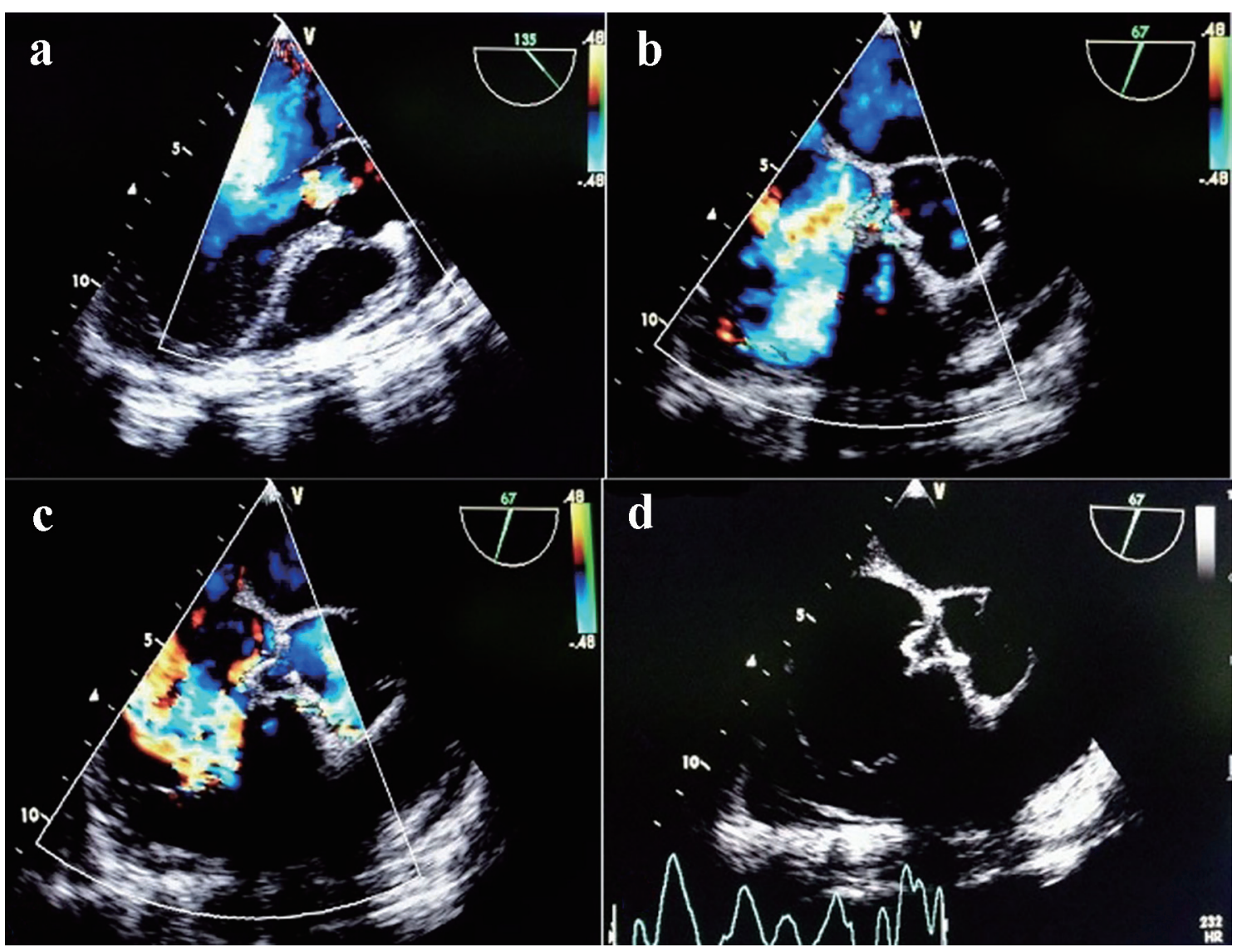

Figure 5. Periprocedural TEE to see degree of aortic leak (a); para-device leak (b); peri devise leak (c); and final position post deployment (d). 


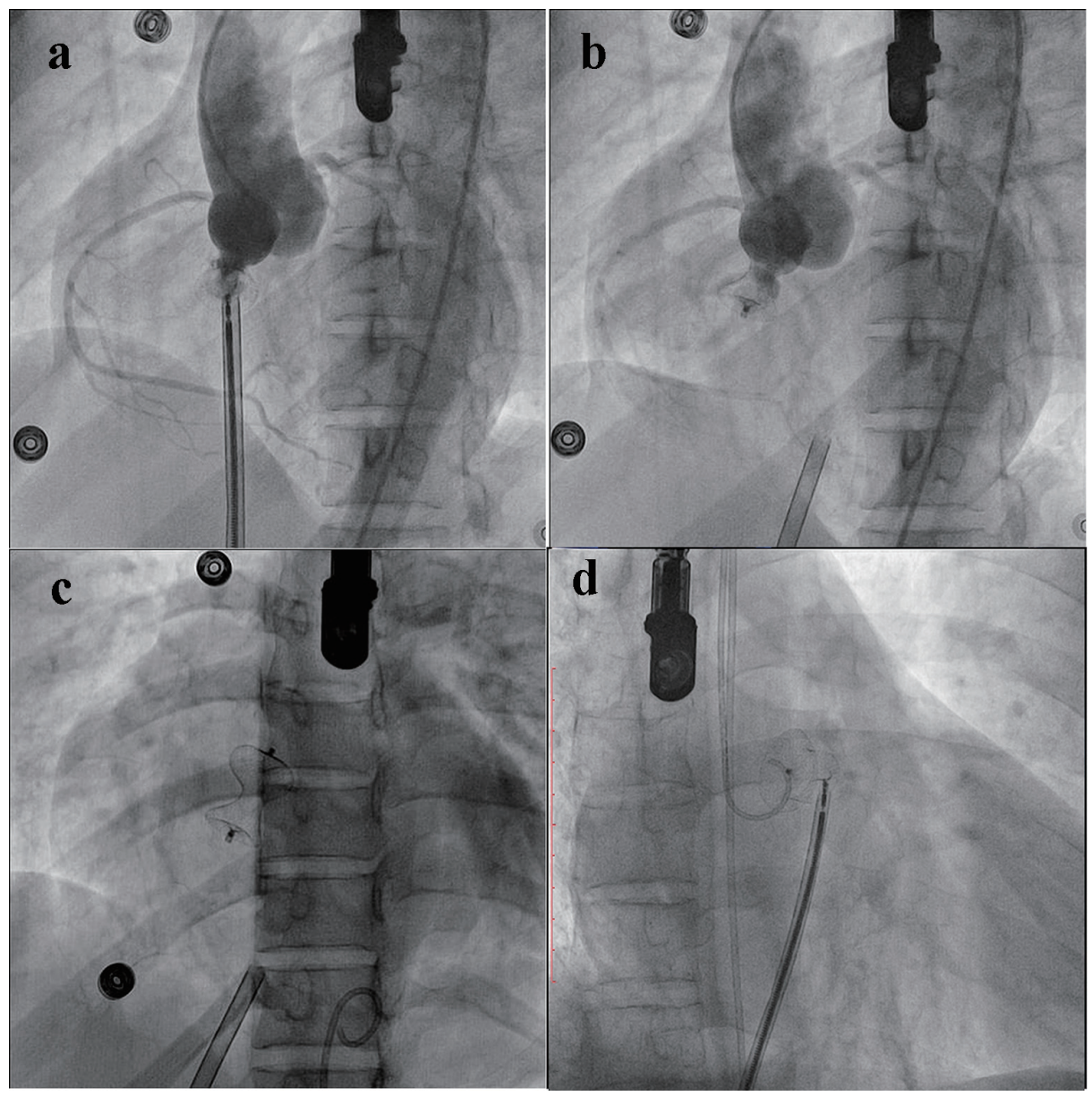

Figure 6. CDO attached to cable with aortic end in right coronary cusp (a); aortic root angiogram to confirm any residual leak (b); final position of deployed device (c); and CDO attached to cable positioned across the RSOVA from right coronary cusp opening into right ventricle $(\mathrm{d})$.

between RCC and RA, and remaining one patient (12.5\%) had defect communicating between RCC and RVOT. In number six patient, initially $18 / 16$ CDO was chosen but as it was not properly anchoring the aortic end, we had to upsize by $20 / 18$ device and completed the procedure. Others were done in single attempt thus achieving procedural success in all six patients $(100 \%)$. We waited for $10 "$ before releasing the device. Five of the eight patients $(60.3 \%)$ had complete disappearance of

Table 1. Baseline Characteristics, Procedural and Follow-Up Data of Patients $(n=8)$

\begin{tabular}{|c|c|c|c|c|c|c|c|c|c|c|}
\hline S. no. & Age/sex & $\begin{array}{l}\text { NYHA } \\
\text { class }\end{array}$ & $\begin{array}{l}\text { Defect } \\
\text { location }\end{array}$ & $\begin{array}{l}\text { Defect size } \\
(\mathrm{mm})\end{array}$ & Associated lesion & $\begin{array}{l}\text { Device } \\
\text { size }\end{array}$ & $\begin{array}{l}\text { Immediate } \\
\text { result }\end{array}$ & $\begin{array}{l}\text { Follow-up } \\
\text { (months) }\end{array}$ & $\begin{array}{l}\text { Residual } \\
\text { shunt }\end{array}$ & $\begin{array}{l}\text { NYHA } \\
\text { class }\end{array}$ \\
\hline 1 & $24 / \mathrm{M}$ & IV & RCC-RA & 17 & Mild AR, BAV & $20 / 18$ & Mild shunt & 13 & None & I \\
\hline 2 & $21 / \mathrm{F}$ & IV & NCC-RA & 9 & None & $12 / 10$ & No shunt & 11 & None & I \\
\hline 3 & $19 / F$ & III & NCC-RA & 14 & None & $18 / 16$ & No shunt & 9 & None & I \\
\hline 4 & $29 / \mathrm{M}$ & IV & RCC-RV & 10 & Severe TR, RVD & $12 / 10$ & No shunt & 12 & None & I \\
\hline 5 & $34 / \mathrm{M}$ & III & NCC-RA & 12 & Healed IE, Mild AR & $16 / 14$ & No shunt & 15 & None & I \\
\hline 7 & $31 / \mathrm{F}$ & III & NCC-RA & 14 & None & $18 / 16$ & Trivial shunt & 22 & None & I \\
\hline 8 & $42 / \mathrm{M}$ & IV & NCC-RA & 12 & Severe TR, RVD & $16 / 14$ & No shunt & 24 & Mild TR & I \\
\hline
\end{tabular}

F: female; M: male; NYHA: New York Heart Association; RCC: right coronary cusp; RA: right atrium; NCC: non-coronary cusp; RVOT: right ventricular outflow tract; AR: aortic regurgitation; BAV: bicuspid aortic valve; TR: tricuspid regurgitation; IE: infective endocarditis; RVD: right ventricular dysfunction. 


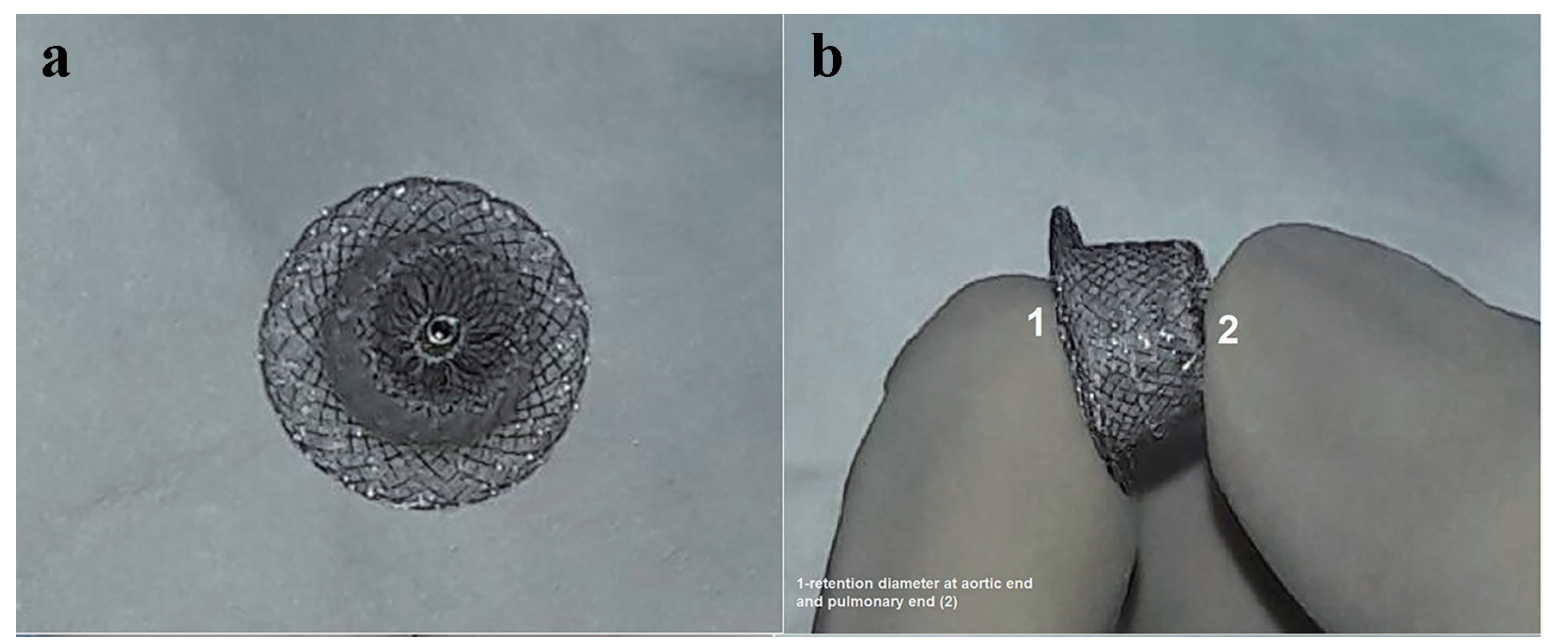

Figure 7. Cocoon duct occluder (a) and retention diameter at aortic and pulmonary end (b).

shunt at the end of procedure while one has mild while another two had trivial residual shunt on check angiogram. On the next day, both had complete disappearance of shunt. Mild AR was present at the baseline in one of the six $(16.6 \%)$ and trivial in another patient $(16.7 \%)$. There was no new or worsening of pre-existing AR. Mean follow-up time was 12 months (range, 9 - 26 months; median, 12 months). All patients improved to NYHA class I. Ecosprin $75 \mathrm{mg}$ was continued for 6 months in all patients.

\section{Discussion}

Aneurysms of SOVA are rare, and, hence, the experience remains limited. Surgery has been the gold standard treatment for RSOVA. However, the morphological features of RSOVA make it amenable to percutaneous closure. RSOV is more common in males with mean age of rupture being third decade [4]. SVA is more often congenital than acquired in origin. Acquired causes include infective endocarditis, syphilis, trauma, connective tissue disorders, Marfan syndrome, atherosclerosis and cystic medial necrosis. SVA comes to clinical attention because of asymptomatic or symptomatic unruptured aneurysm. Patients succumb to death from congestive heart failure usually within a year after rupture if left untreated; however, longer survival after small slow perforation is well described. SVA can present in various ways such as rupture into cardiac chamber with subsequent cardiac failure, acute coronary syndrome, cardiac tamponade, heart block, aortic regurgitation and RVOT obstruction [5]. Majority of SVA arising from right coronary sinus ruptures in right ventricle and those arising from non-coronary sinus ruptures into RA [6].

The technique is similar to TCC of perimembranous VSD, although the defect is located just above the aortic valve instead of below. Periprocedural TEE and color Doppler interrogation help us in sizing the defect, device selection (2 - $4 \mathrm{~mm}$ larger than the aortic end), delineating the SOVA anatomy in regards to its neighboring structures namely the aortic valve, tricuspid valve, and RVOT, ensuring proper seating of the aor- tic disk on the aortic side without slipping into the body of the aneurysm, and most importantly, monitoring AR and TR occurrence and residual shunting on color Doppler. Although Arora et al [8] have used TTE, we believe that TEE guidance makes procedure much comfortable. Unlike Arora et al [8], we did not utilize balloon sizing of the defect since we were able to size the defect well on TEE. We attempted to close the RSOVA at the aortic end similar to a "surgeon's repair", not into the "windsock" as closure at the rupture site (exit point) would leave behind an aneurismal sac exposed to arterial pressure with a potential to rupture at another site in the long term [9].

TCC of RSOVA has been performed by using ADO, VSD occluder, ASD occluder, Gianturco coils and Rashkind umbrella [8-13] with variable success. Sinha et al [14] in their series of eight patients, largest till date with use of CDO had success rate of $87.5 \%$. In their series, largest defect size was 10 $\mathrm{mm}$ and largest size of device was $14 / 12 \mathrm{~mm}$ and defects of 14 $\mathrm{mm}$ or more were referred to surgical correction. In our study, three patients $(50 \%)$ had size $\geq 14 \mathrm{~mm}$ which were successfully interrupted with CDO and largest size of device was 20/18. Defects larger than $10 \mathrm{~mm}$ were closed by Guan et al using 14 - $18 \mathrm{~mm}$ PDA device [10]. The potential problem with the bigger device is worsening of pre-existing, development of new AR or coronary ostial pinching but we encountered none. We checked all results with the TEE as well as the concluding aortic root angiogram. We had one patient with healed IE before device implant, who is stable after 15 months of follow-up. We had procedural success of $100 \%$ and to the best of our knowledge, have used biggest CDO till date.

The CDO (Fig. 7a, b) is a surgical permanent implant. It is a platinum-coated self-expandable, mushroom-shaped device made from a Nitinol wire mesh. A mushroom-shaped retention skirt assures secure positioning at the aortic orifice of patent ductus arteriosus. The communication is closed by the introduction of thrombosis which is accomplished by multiple poly propylene patches sewn securely to the side of the device. Nanoplatinum coating provides superior bio-compatible properties compared to bare nitinol and prevents nickel leaching into the blood stream and corrosion of nitinol wire frame in long- 
term implants. Platinum provides better radio opacity which enables easy positioning of the device in the defect.

\section{Conclusion}

TCC of RSOVA is safe, effective and can be performed for bigger defect ( $>14 \mathrm{~mm}$ ) using $\mathrm{CDO}$ and is a good alternative to surgery. However, still a longer-term follow-up is needed.

\section{Conflicts of Interest}

None.

\section{Financial Disclosure}

None.

\section{References}

1. Kirklin JW, Barratt-Boyes BG. Congenital sinus of Valsalva aneurysm and aortic left ventricular tunnel. In: Kirklin JW, Barratt-Boyes BG, eds. Cardiac Surgery. 3rd Ed. New York: Churchill-Livingstone; 2003: p. 911-927.

2. Sakakibara S, Konno S. Congenital aneurysm of the sinus of Valsalva. Anatomy and classification. Am Heart J. 1962;63:405-424.

3. Edwards JE, Burchell HB. The pathological anatomy of deficiencies between the aortic root and the heart, including aortic sinus aneurysms. Thorax. 1957;12(2):125-139.

4. Cullen S, Somerville J, Redington A. Transcatheter closure of a ruptured aneurysm of the sinus of Valsalva. $\mathrm{Br}$ Heart J. 1994;71(5):479-480.

5. Rao PS, Bromberg BI, Jureidini SB, Fiore AC. Transcatheter occlusion of ruptured sinus of valsalva aneurysm: innovative use of available technology. Catheter Cardiovasc Interv. 2003;58(1):130-134.

6. Fedson S, Jolly N, Lang RM, Hijazi ZM. Percutaneous closure of a ruptured sinus of Valsalva aneurysm using the Amplatzer Duct Occluder. Catheter Cardiovasc Interv. 2003;58(3):406-411.

7. Kerkar P, Suvarna T, Burkule N, Panda R. Transcatheter closure of ruptured sinus of Valsalva aneurysm using the Amplatzer duct occluder in a critically ill post-CABG patient. J Invasive Cardiol. 2007;19(6):E169-171.

8. Arora R, Trehan V, Rangasetty UM, Mukhopadhyay $\mathrm{S}$, Thakur AK, Kalra GS. Transcatheter closure of ruptured sinus of valsalva aneurysm. J Interv Cardiol. 2004;17(1):53-58.

9. Kerkar PG, Lanjewar CP, Mishra N, Nyayadhish P, Mammen I. Transcatheter closure of ruptured sinus of Valsalva aneurysm using the Amplatzer duct occluder: immediate results and mid-term follow-up. Eur Heart J. 2010;31(23):2881-2887.

10. Guan L, Zhou D, Zhang F, Pan W, Dong L, Chen H, Ge J. Percutaneous device closure of ruptured sinus of valsalva aneurysm: a preliminary experience. J Invasive Cardiol. 2013;25(10):492-496.

11. Chang CW, Chiu SN, Wu ET, Tsai SK, Wu MH, Wang JK. Transcatheter closure of a ruptured sinus of valsalva aneurysm. Circ J. 2006;70(8):1043-1047.

12. Zhao SH, Yan CW, Zhu XY, Li JJ, Xu NX, Jiang SL, Xu ZY, et al. Transcatheter occlusion of the ruptured sinus of Valsalva aneurysm with an Amplatzer duct occluder. Int J Cardiol. 2008;129(1):81-85.

13. Sen S, Chattopadhyay A, Ray M, Bandyopadhyay B. Transcatheter device closure of ruptured sinus of Valsalva: Immediate results and short term follow up. Ann Pediatr Cardiol. 2009;2(1):79-82.

14. Sinha SC, Sujatha V, Mahapatro AK. Percutaneous transcatheter closure of ruptured sinus of valsalva aneurysm: immediate result and long-term follow-up. Int J Angiol. 2015;24(2):99-104. 